\begin{tabular}{|c|c|c|}
\hline & $\begin{array}{l}\text { Bioeduca: Journal of Biology Education } \\
\text { http://journal.walisongo.ac.id/index.php/bioeduca } \\
\text { ISSN 2714-8009 (print), 2715-7490 (online) }\end{array}$ & BBOEDUCA \\
\hline WALISONGO & $\begin{array}{c}\text { Volume 2, Nomor 1, Tahun } 2020 \\
\text { Hal. } 1-8\end{array}$ & \\
\hline
\end{tabular}

\title{
Pengembangan Booklet Keanekaragaman Lepidoptera Subordo Rhopalocera di Kawasan Cagar Alam Pagerwunung Darupono Kendal Sebagai Sumber Belajar Biologi pada Materi Keanekaragaman Hayati di Madrasah Aliyah
}

\author{
Fitrotun Nafsiyah ${ }^{1}$ \\ ${ }^{1}$ Pendidikan Biologi, Univeristas Islam Negeri Walisongo Semarang \\ *Email: fitrotunnafsiyah03@gmail.com
}

\begin{tabular}{|c|c|}
\hline Informasi Artikel & ABSTRAK \\
\hline $\begin{array}{l}\text { Submit: } 10-08-2019 \\
\text { Diterima: } 12-12-2019 \\
\text { Dipublikasikan: } 12-03-2020\end{array}$ & $\begin{array}{l}\text { Tujuan penelitian ini yaitu menjelaskan jenis Lepidoptera } \\
\text { Subordo Rhopalocera yang ada di kawasan Cagar Alam } \\
\text { Pagerwunung Darupono Kendal dan menjelaskan kelayakan } \\
\text { booklet tentang Keanekaragaman Rhopalocera di kawasan } \\
\text { Cagar Alam Pagerwunung sebagai sumber belajar Biologi kelas } \\
\text { X MA NU } 03 \text { Sunan Katong Kaliwungu Kendal. Metode penelitian } \\
\text { adalah Research and Development (R\&D) dengan model Borg \& } \\
\text { Gall yang dimodifikasi. Subjek penelitian ini adalah peserta didik } \\
\text { kelas X MIPA } 1 \text { dan X MIPA } 2 \text { MA NU } 03 \text { Sunan Katong yang } \\
\text { berjumlah } 18 \text { siswa. Hasil penelitian menunjukkan jenis } \\
\text { Rhopalocera yang ditemukan di kawasan Cagar Alam } \\
\text { Pagerwunung berjumlah } 29 \text { spesies yang terbagi atas } 4 \text { famili } \\
\text { yaitu Nymphalidae berjumlah } 15 \text { spesies, Papilionidae } 6 \text { spesies, } \\
\text { Pieridae } 6 \text { spesies, dan Lycaenidae } 2 \text { spesies. Uji kelayakan oleh } \\
\text { ahli materi sebesar } 92 \% \text {, penilaian dari ahli media sebesar } \\
74,54 \% \text {, penilaian oleh guru biologi sebanyak } 91,30 \% \text {, serta } \\
\text { penilaian dari peserta didik sebanyak } 84,6 \% \text { yang menunjukkan } \\
\text { kategori sangat layak. } \\
\text { Kata kunci: rhopalocera; booklet; MA NU } 03 \text { Sunan Katong. }\end{array}$ \\
\hline Penerbit & ABSTRACT \\
\hline $\begin{array}{l}\text { Program Studi Pendidikan } \\
\text { Biologi, Fakultas Sains dan } \\
\text { Teknologi, UIN Walisongo } \\
\text { Semarang }\end{array}$ & $\begin{array}{l}\text { The purpose of this study is to explain the types of Lepidoptera } \\
\text { Subordo Rhopalocera in the Pagerwunung Darupono Kendal } \\
\text { Nature Reserve and to explain the feasibility of a booklet on } \\
\text { Rhopalocera Diversity in the Pagerwunung Nature Reserve as a } \\
\text { learning resource for class X MA NU } 03 \text { Sunan Katong Kaliwungu } \\
\text { Kendal. The research method is Research and Development } \\
\text { (R\&D) with a modified Borg \& Gall model. The subjects of this } \\
\text { study were } 18 \text { students of class X MIPA } 1 \text { and X MIPA } 2 \text { MA NU } \\
\text { O3 Sunan Katong. The results showed that there were } 29 \text { species } \\
\text { of Rhopalocera found in the Pagerwunung Nature Reserve which } \\
\text { were divided into } 4 \text { families, namely } 15 \text { species of Nymphalidae, } \\
6 \text { species of Papilionidae, } 6 \text { species of Pieridae, and } 2 \text { species of } \\
\text { Lycaenidae. The feasibility test by material experts was } 92 \% \text {, the } \\
\text { media expert's assessment was } 74.54 \% \text {, the biology teacher's } \\
\text { assessment was } 91.30 \% \text {, and the students' assessment was } \\
84.6 \% \text { which showed that the category was very feasible. Based } \\
\text { on this percentage, the booklet can be said to be very suitable for } \\
\text { use as a learning resource. } \\
\text { Keywords: rhopalocera; booklet; MA NU } 03 \text { Sunan Katong. }\end{array}$ \\
\hline
\end{tabular}

Copyright (2020, Bioeduca: Journal of Biology Education

Fitrotun Nafsiyah et al.- Pengembangan Booklet Keanekaragaman Lepidoptera Subordo Rhopalocera Di Kawasan Cagar Alam Pagerwunung Darupono Kendal Sebagai Sumber Belajar Biologi pada Materi Keanekaragaman Hayati di Madrasah Aliyah 


\section{PENDAHULUAN}

Kegiatan belajar mengajar merupakan kegiatan yang paling pokok dalam keseluruhan proses pendidikan. Pencapaian tujuan pembelajaran bergantung pada proses belajar mengajar yang dirancang dan dijalankan secara profesional. Setiap pembelajaran selalu melibatkan dua pelaku aktif, yaitu guru dan siswa. Perilaku guru adalah mengajar dan perilaku siswa adalah belajar (Rusman, 2016:1). Guru sebagai pengajar merupakan pencipta kondisi belajar siswa yang didesain dengan sengaja, sistematis, dan berkesinambungan. Sedangkan siswa sebagai peserta didik merupakan pihak yang mengikuti kegiatan belajar yang diciptakan oleh guru. Kegiatan pembelajaran di sekolah sangat penting, karena dapat mempengaruhi hasil belajar siswa atau prestasi yang dicapai. Pembelajaran yang efektif dipengaruhi oleh beberapa faktor, salah satunya adalah media pembelajaran yang digunakan oleh guru. Melalui media pembelajaran, guru dapat menyajikan bahan pelajaran yang bersifat abstrak menjadi konkret sehingga mudah dipahami. Media pembelajaran juga dapat mempermudah pemahaman siswa terhadap kompetensi yang harus dikuasai, yang pada akhirnya diharapkan dapat meningkatkan hasil belajar siswa.

Dalam proses pembelajaran terdapat komponen-komponen belajar yang harus ada agar tujuan pendidikan dapat tercapai. Salah satu komponen dalam belajar adalah sumber belajar. Sumber belajar merupakan salah satu komponen yang membantu dalam proses belajar mengajar. Sumber belajar adalah daya yang dapat dimanfaatkan guna kepentingan proses belajar mengajar, baik secara langsung maupun tidak langsung (Rusman, 2009: 130). Agar mampu mengidentifikasi dan memanfaatkan berbagai potensi sumber belajar secara maksimal, maka hal yang harus dilakukan adalah mengenali berbagai bentuk sumber belajar tersebut. Bentuk-bentuk sumber belajar antara lain yaitu buku, brosur, koran, booklet, poster, ensiklopedia, film,slides, video, model, dan lain sebagainya (Prastowo, 2018: 45). Agar tercipta kegiatan pembelajaran yang efektif dan menyenangkan bagi siswa, maka sumber belajar yang digunakan harus menarik. Media yang menarik, seperti gambar dapat memotivasi siswa dalam pembelajaran dan dapat meningkatkan kemampuan siswa dalam mengingat materi. Dalam proses pembelajaran guru dapat mengaitkan materi keanekaragaman hayati dengan memanfaatkan alam yang ada, sehingga siswa dapat melihat objek yang sangat beragam yang diciptakan oleh Allah. Keanekaragaman Hayati merupakan salah satu pokok bahasan pelajaran Biologi kelas X semester satu yaitu dari KD 3.2 Menganalisis berbagai tingkat keanekaragaman hayati di Indonesia beserta ancaman dan pelestariannya dan 4.2 Menyajikan hasil observasi berbagai tingkat keanekaragaman hayati di Indonesia dan usulan upaya pelestariannya. Kompetensi dasar tersebut mengacu pada KD Permendikbud Nomor 24 Tahun 2016. Dalam Kompetensi Dasar tersebut siswa dituntut untuk dapat mengelompokkan dan membedakan berbagai tingkat keanekaragaman hayati. Cakupan materi di dalamnya meliputi: pengertian keanekaragaman hayati, tingkat keanekaragaman hayati, persebaran flora dan fauna di Indonesia, manfaat keanekaragaman hayati, dan sistem klasifikasi makhluk hidup. 
Hasil wawancara dengan guru biologi di MA NU 03 Sunan Katong yang bernama ibu Tumiyati, S.Pd pada tanggal 28 Maret 2018 bahawa proses pembelajaran di kelas $X$ sering menggunakan metode ceramah serta diskusi dengan menggunakan buku paket sebagai bahan ajar utama. Siswa kurang berperan aktif dalam pembelajarannya. Materi keanekaragaman hayati kurang dipahami jika hanya menggunakan metode ceramah saja. Hal ini dapat mengakibatkan kurangnya pemahaman siswa terhadap materi tersebut.

Cagar Alam Pagerwunung Darupono merupakan salah satu cagar alam di wilayah Jawa Tengah yang terletak di wilayah Desa Darupono, Kecamatan Kaliwungu, Kabupaten Kendal. Potensi flora yang dimiliki oleh cagar alam ini antara lain yaitu jati (Tectona grandis), klayu, jengkol, belimbing dan lainnya. Selain tumbuhan, cagar alam Pagerwunung Darupono juga memiliki potensi fauna yang melimpah. Salah satunya adalah keanekaragaman jenis Lepidoptera subordo Rhopalocera (kupu-kupu). Jenis kupu-kupu yang terdapat di kawasan Cagar Alam Pagerwunung Darupono cukup banyak, hal ini dikarenakan ketersediaan tumbuhan yang terdapat di kawasan tersebut dapat menunjang kelangsungan hidup kupu-kupu yang berada di kawasan tersebut. Kupu-kupu memiliki nilai yang sangat penting, yang dapat dikelompokkan kedalam nilai ekonomi, ekologi, endemis, konservasi, estetika, dan pendidikan. Namun keberadaan kawasan tersebut belum digunakan secara maksimal dalam kegiatan belajar mengajar. Kawasan tersebut memiliki potensi untuk bisa dijadikan sebagai sumber belajar dalam kegiatan belajar mengajar.

Berdasarkan permasalahan tersebut, maka solusi alternatif yang dapat diberikan adalah penggunaan booklet yang berisi tentang keanekaragaman Lepidoptera Subordo Rhopalocera (Kupu-kupu) di kawasan Cagar Alam Pagerwunung Darupono Kaliwungu Kendal. Data hasil penelitian keanekaragaman Lepidoptera di Kawasan Cagar Alam Pagerwunung Darupono Kendal yang berbentuk Booklet diharapkan dapat digunakan sebagai sumber belajar tambahan siswa kelas $\mathrm{X}$ MA NU 03 Kaliwungu Kendal pada mata pelajaran Biologi.

\section{METODE PENELITIAN}

Penelitian ini termasuk jenis penelitian dan pengembangan atau Research and Development (R \& D) (Sugiyono, 2017:407). Model pengembangan dalam penelitian ini adalah 10 langkah Borg \& Gall yaitu potensi masalah, pengumpulan informasi atau data, desain produk, validasi desain, revisi desain, uji coba produk, revisi produk, uji coba pemakaian, revisi produk, tahap akhir, dan produksi masal (Sugiyono, 2016: 408409). Dalam penelitian ini hanya dibatasi sampai pada tahap uji coba produk booklet, tidak sampai pada revisi produk, uji coba pemakaian dan produksi massal.

Penelitian dilakukan pada bulan November tahun 2019 di MA NU 03 Sunan Katong Kaliwungu Kendal. Subjek dari peneltian ini adalah siswa kelas X MA NU 03 Sunan Katong Kaliwungu. Uji coba produk diterapkan pada siswa kelas X MIPA 1 dan MIPA 2 dengan skala kecil yaitu pada 18 siswa, dengan kategori pemahaman tingkat tinggi, pemahaman tingkat sedang, dan pemahaman tingkat rendah. 
Pengambilan sampel kupu-kupu menggunakan metode transek garis. Pengambilan sampel dilakukan dengan menentukan titik pengambilan sampel. Pada penelitian ini garis transek utama diletakkan sepanjang hutan yaitu kawasan CA 56b dengan luas 12 ha dan CA 25b dengan luas 21,2 ha. Jalur ini terletak memanjang yang membagi Cagar Alam Alam Pagerwunung Darupono menjadi wilayah sempit dan luas. Terdapat 6 subtransek dengan jarak antar subtransek yaitu $200 \mathrm{~m}$. Setiap sub transek terdapat titik pengamatan. Jarak antartitik pengamatan adalah $150 \mathrm{~m}$. pada setiap titik memiliki luas $500 \mathrm{~m}^{2}(20 \mathrm{~m} \times 25 \mathrm{~m})$. Pengamatan kupu-kupu dilakukan pada pukul 08.00-15.00 WIB.

Teknik pengumpulan data yang digunakan dalam penelitian adalah teknik observasi, teknik wawancara, karakterisasi, identifikasi, dokumentasi, dan kuesioner (angket). Analisis data dalam penelitian ini dilakukan dengan teknik analisis data kualitatif dan analisis kuantitatif. Data kualitatif dalam penelitian diperoleh dari hasil observasi dan wawancara. Data yang diperoleh selama proses penelitian dijabarkan secara deskriptif kemudian ditarik kesimpulan. Analisis data kuantitatif dilakukan untuk mengolah data berupa skor penilaian ahli materi, ahli media, guru, dan siswa. Data yang diperoleh selanjutnya dianalisis secara kualitatif dengan menggunakan instrumen angket yang berupa simbol angka-angka bertingkat. Angka bertingkat tersebut adalah 5, 4, 3, 2, 1 yaitu simbol yang menunjukkan urutan tingkatan karena datanya berupa data ordinal (Arikunto, 2013:201). Data yang diperoleh kemudian dihitung persentasenya dengan rumus sebagai berikut (Sugiyono, 2013):

Kemudian data dianalisis dan disederhanakan dalam bentuk yang lebih mudah dibaca dan diinterpretasikan agar diperoleh kesimpulan mengenai kelayakan booklet keanekaragaman Lepidoptera Subordo Rhopalocera di Kawasan Cagar Alam Pagerwunung Darupono Kaliwungu Kendal termasuk ke dalam kategori sangat layak, layak, kurang layak, tidak layak, dan sangat tidak layak. Kriteria kelayakan menurut Akbar (2013:49) adalah 81-100\% sangat layak, 61-80\% layak, 41-60\% kurang layak, $21-40 \%$ tidak layak, dan $0-20 \%$ sangat tidak layak.

\section{HASIL PENELITIAN DAN PEMBAHASAN}

Penelitian ini memiliki dua jenis data yaitu data kualitatif dan data kuantitatif. Data kualitatif diperoleh dari hasil observasi dan wawancara. Sedangkan data kuantitatif diperoleh dari hasil penilaian angket yang berupa skor penilaian ahli materi, ahli media, guru, dan siswa.

Pengembangan produk yang dilakukan oleh peneliti menggunakan langkahlangkah pengembangan yang digunakan oleh Sugiyono (2016: 297). Tahapan yang pertama, potensi dan masalah pada tahapan dilakukan analisis kebutuhan sumber belajar yaitu dengan melakukan wawancara dengan guru biologi dan siswa. Berdasarkan hasil wawancara dengan guru, diperoleh informasi bahwa proses pembelajaran di kelas $X$ sering menggunakan metode ceramah serta diskusi dengan menggunakan buku paket sebagai bahan ajar utama. Hal itu menyebabkan siswa kurang berperan aktif dalam proses pembelajaran. 
Tahap kedua, yaitu pengumpulan data. Pada tahap pengumpulan data diambil dari identifikasi potensi dan masalah yang ditemukan saat melakukan observasi di Cagar Alam Pagerwunung dan wawancara oleh peneliti. Hasil penelitian di kawasan Cagar Alam Pagerwunung Darupono menunjukkan bahwa kupu-kupu yang ditemukan berjumlah 29 spesies yang terbagi atas 4 kelompok famili yaitu Nymphalidae (Neptis hylas, Junonia hedonia, Danaus genutia, Euploea tulliolus, Ideopsis juventa, Ideopsis vulgaris, Junonia almana, Hypolimnas bolina, Euploea mulciber, Junonia orithya, Kallima paralekta, Junonia iphita, Euploea crameri, Ypthima baldus, Elymnias hypermnestra), Papilionidae (Papilio polytes, Papilio helenus, Pachliopta aristolochiae, Graphium agamemnon, Graphium doson, Graphium decolor), Pieridae (Catopsilia pyranthe, Leptosia nina, Cepora Judith, Catosilia Pomona, Appias libythea, Eurema hecabe), dan Lycaenidae (Curetis thetis, dan Jamides elpis).

Tahap ketiga, desain produk. Pada tahapan ini peneliti merancang dan menghasilkan produk berupa booklet, yang terdiri dari beberapa langkah yaitu penyusunan isi materi, pemilihan media, pemilihan format, dan rancangan awal produk.

Tahap keempat, validasi produk. Pada tahap ini produk divalidasi oleh ahli materi dan ahli media untuk mengetahui kelayakan produk booklet.

Hasil uji kelayakan ahli materi dapat dilihat pada gambar 1 berikut :

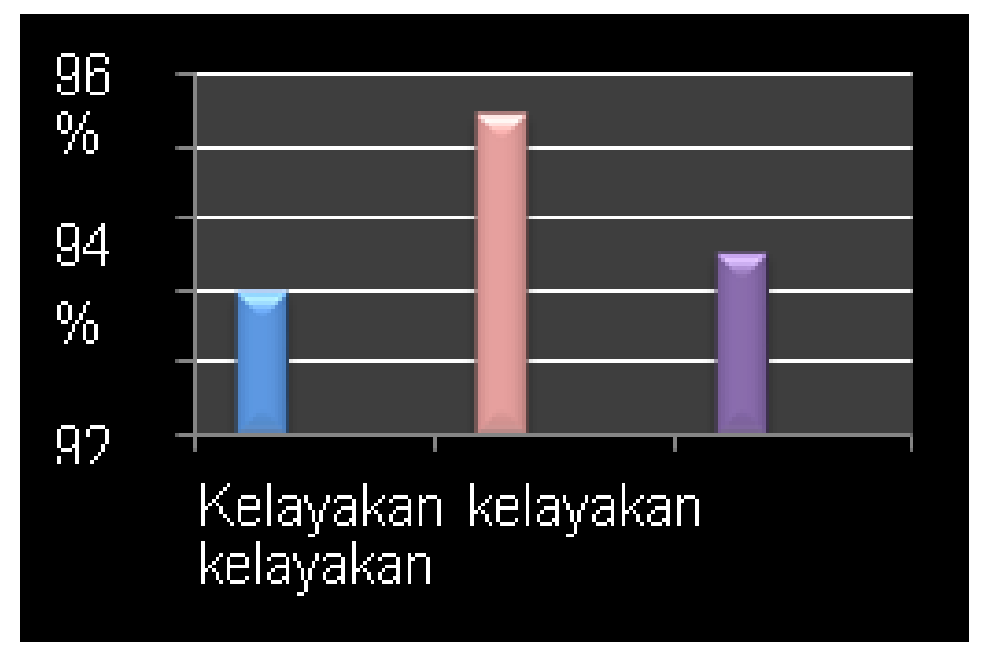

Gambar 1. Grafik hasil uji kelayakan oleh validasi materi

Berdasarkan grafik diatas menunjukkan aspek penilaian kelayakan isi mencapai persentase $90 \%$, yang artinya sangat layak, kelayakan penyajian mencapai persentase $95 \%$, yang artinya sangat layak, dan aspek penilaian bahasa mencapai persentase $91,1 \%$, yang artinya sangat layak. Kemudian dihitung dari ketiga aspek penilaian materi menunjukkan rata-rata persentase kelayakan yang mencapai $92 \%$. Persentase tersebut dikatakan sangat layak untuk dijadikan sumber belajar.

Hasil uji kelayakan ahli media dapat dilihat pada gambar 2 berikut :

Fitrotun Nafsiyah et al.- Pengembangan Booklet Keanekaragaman Lepidoptera Subordo 


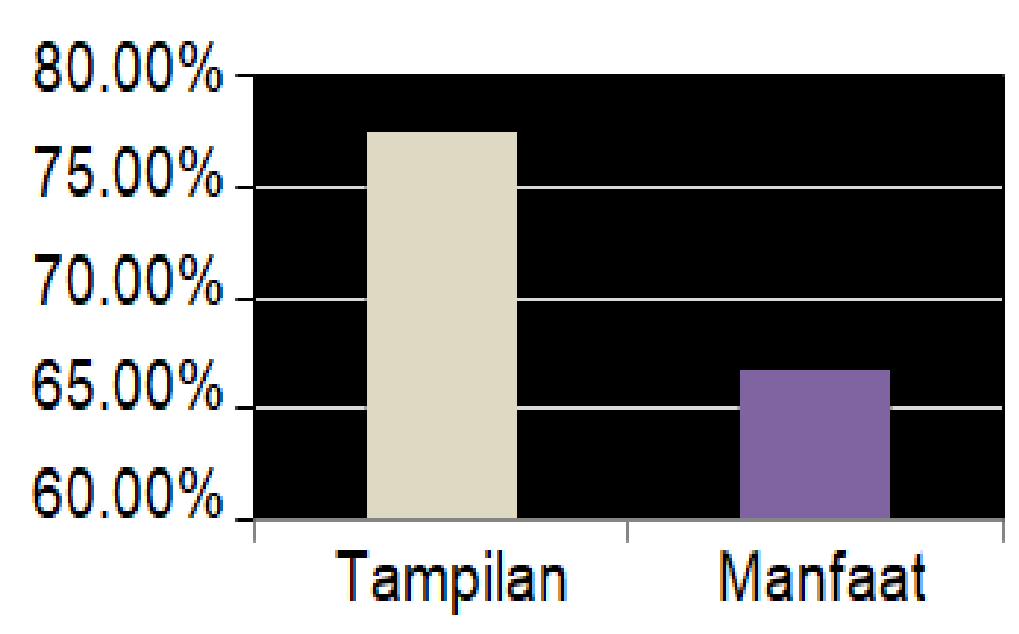

Gambar 2. Grafik hasil uji kelayakan oleh validasi media

Berdasarkan grafik diatas menunjukkan bahwa aspek penilaian kelayakan tampilan mencapai persentase $77,5 \%$, yang artinya aspek kelayakan tampilan dapat dikatakan layak. Pada aspek penilaian manfaat mencapai persentase $66,7 \%$, yang artinya aspek kemanfaatan dapat dikatakan layak. Kemudian dihitung dari kedua aspek penilaian media menunjukkan rata-rata persentase kelayakan yang mencapai 74,54\%. Menurut Sa'dun Akbar (2013:49) persentase tersebut dikatakan layak untuk dijadikan sumber belajar.

Tahap kelima, revisi produk. Produk booklet yang sudah diuji kelayakan oleh validator ahli materi dan ahli media, langkah selanjutnya yaitu melakukan revisi produk sesuai dengan masukan yang diberikan oleh validator ahli. Revisi produk digunakan untuk mengetahui kekurangan dan kelebihan dari booklet.

Tahap keenam, uji coba lapangan. Setelah produk selesai melalui tahapan validasi oleh ahli materi dan ahli media, maka selanjutnya produk diujicobakan kepada guru Biologi $X$. Tujuannya adalah untuk mengetahui respon terhadap produk yang telah dikembangkan oleh peneliti.

Hasil penilaian booklet oleh guru biologi dapat dilihat pada gambar 3 berikut :

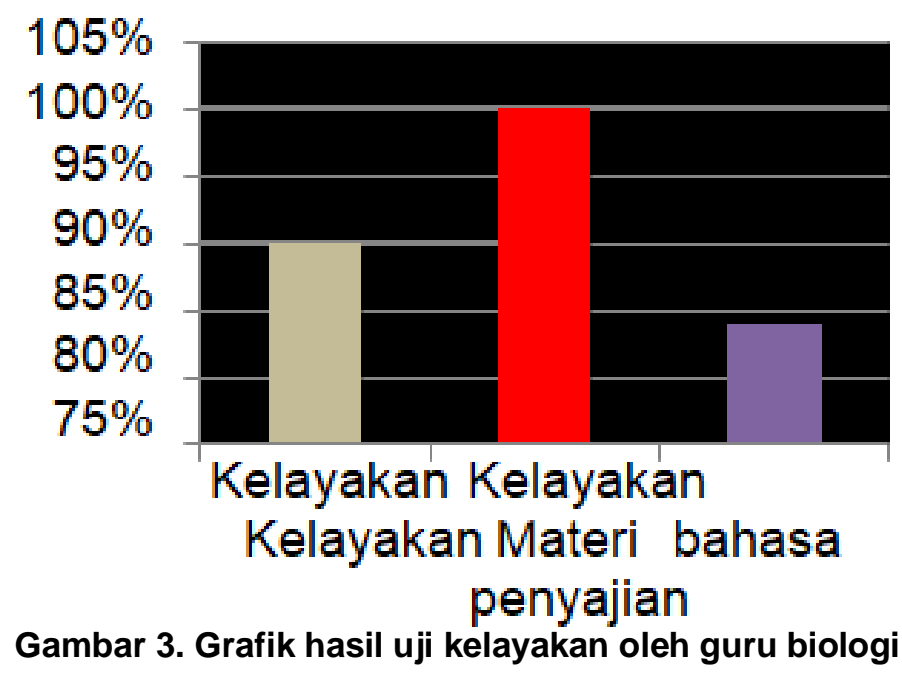
Rhopalocera Di Kawasan Cagar Alam Pagerwunung Darupono Kendal Sebagai Sumber Belajar Biologi pada Materi Keanekaragaman Hayati di Madrasah Aliyah 
Kelayakan booklet berdasarkan penilaian oleh guru biologi menunjukkan bahwa aspek penilaian kelayakan materi mencapai persentase $90 \%$, yang artinya sangat layak. Pada aspek penilaian bahasa mencapai persentase $100 \%$, yang artinya sangat layak. Sedangkan pada aspek kelayakan penyajian mencapai persentase $84 \%$ yang dapat diartikan juga sangat layak. Kemudian dihitung dari ketiga aspek penilaian oleh guru biologi menunjukkan rata-rata persentase kelayakan yang mencapai 91,30\%. Menurut Sa'dun Akbar (2013:49) persentase tersebut dikatakan sangat layak untuk dijadikan sumber belajar.

Produk yang telah divalidasi oleh ahli materi, ahli media, dan guru biologi, maka selanjutnya diujicobakan pada skala kecil dengan jumlah siswa yang terbatas.

Hasil angket respon siswa terhadap produk booklet dapat dilihat pada gambar 4 berikut :

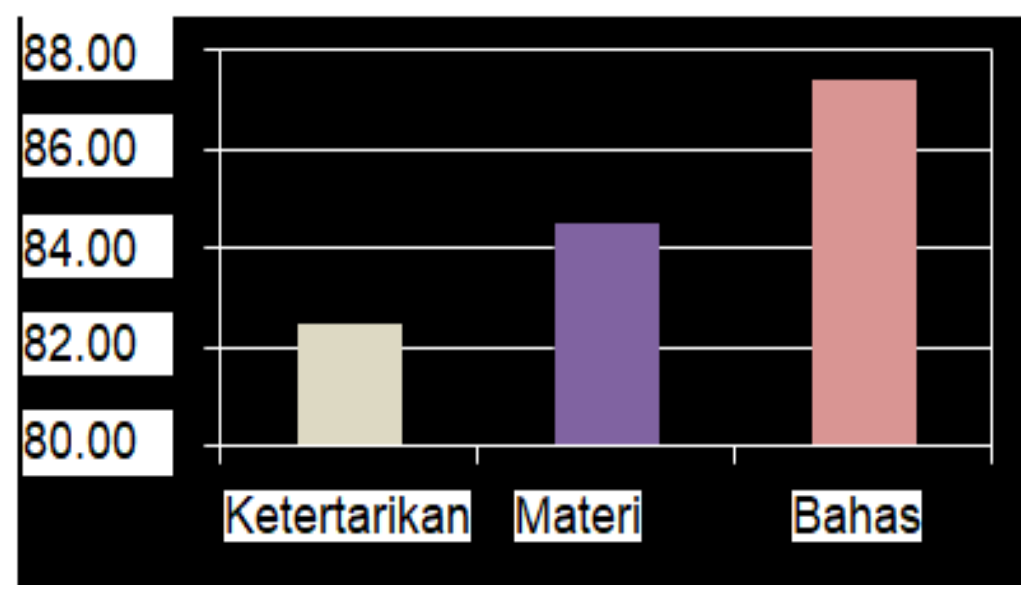

Gambar 4. Grafik hasil uji kelayakan oleh siswa

Kelayakan booklet berdasarkan penilaian responden menunjukkan kelayakan yang dapat dilihat dari tiga aspek, yaitu ketertarikan, materi, dan bahasa. Aspek ketertarikan diperoleh hasil persentase $82,5 \%$ yang merupakan kategori sangat layak, aspek materi diperoleh hasil persentase $84,5 \%$ yang merupakan kategori sangat layak, dan aspek kebahasaan memperoleh rata-rata persentase $87,4 \%$ yang menunjukkan kategori sangat layak. perhitungan secara keseluruhan diperoleh skor rata-rata persentase sebesar $84,6 \%$ yang menunjukkan kategori sangat layak.

\section{SIMPULAN DAN SARAN}

Berdasarkan hasil penelitian dan pengembangan yang telah dilakukan dapat disimpulkan Rhopalocera (kupu-kupu) yang ditemukan di Kawasan Cagar Alam Pagerwunung Darupomo Kendal berjumlah 29 spesies yang terbagi atas 4 kelompok famili yaitu Nymphalidae (Neptis hylas, Junonia hedonia, Danaus genutia, Euploea tulliolus, Ideopsis juventa, Ideopsis vulgaris, Junonia almana, Hypolimnas bolina, Euploea mulciber, Junonia orithya, Kallima paralekta, Junonia iphita, Euploea crameri, Ypthima baldus, Elymnias hypermnestra), Papilionidae (Papilio polytes, Papilio helenus, Pachliopta aristolochiae, Graphium agamemnon, Graphium doson, 
Graphium decolor), Pieridae (Catopsilia pyranthe, Leptosia nina, Cepora Judith, Catosilia Pomona Appias libythea, Eurema hecabe), dan Lycaenidae (Curetis thetis, dan Jamides elpis). Booklet Keanekaragaman Lepidoptera Subordo Rhopalocera di Kawasan Cagar Alam Pagerwunung Darupono Kendal oleh ahli materi termasuk dalam kategori sangat layak dengan persentase rata-rata yaitu sebesar $92 \%$, penilaian dari ahli media termasuk dalam kategori layak dengan persentase penilaian sebanyak $74,54 \%$, penilaian oleh guru biologi persentase rata-rata yaitu $91,30 \%$, serta penilaian dari siswa memperoleh rata-rata persentase sebanyak $84,6 \%$ yang menunjukkan kategori sangat layak. Oleh karena itu, booklet dapat dikatakan sangat layak digunakan sebagai sumber belajar.

\section{RUJUKAN}

Alghifari, S. (2016). Keanekaragaman Jenis Paku Terestrial dikawasan Gunung Bunder Taman Nasional Gunung Halimn Salak (Bogor) Jawa Barat. Skripsi. Bogor: IPB University

Arini, D. I. D dan Kinho, J. (2012).Keragaman Jenis Tumbuhan Paku (Pteridophyta) di Cagar Alam Gunung Ambang Sulawesi Utara. Jurnal Kehutanan. 2 (1) : 1-24 Betty, Julia, dkk. (2015). Inventarisasi Jenis Paku-pakuan (pterydophyta) Terestrial di Hutan Dusun Tauk Kecamatan Air Besar Kabupaten Landak. Jurnal Protobiont Vol.4

Holttum, R.E dan Allen, B.M. (1967). Fern of Malaya (Revised Flora of Malaya, Vol.II). Singapura: Government Printing Office Singapura

Hoshizaki, B.J dan Moran, R.C. (2001). Fern Grower's Manual. USA : Timber Press Lubis, S.R. 2009. "Keanekaragaman dan Pola Distribusi Tumbuhan Paku di Hutan Wisata Alam Taman Eden Kabupaten Toba Samosir Provinsi Sumatra Utara".Tesis. Medan: Universitas Sumatra Utara

Mochamad, Primack, Supriatna. (2007). Biologi Konservasi Edisi Revisi. Jakarta : Yayasan Obor Indonesia Tjitrosoepomo, G. 2009.Taksonomi Tumbuhan (Schizophyta, Thallophyta, Bryophyta, Pteridophyta). Yogyakarta: UGM Press

Rusman. (2016). Model-Model Pembelajaran Mengembangkan Profesionalisme Guru. Jakarta: Rajawali Pers.

Rusman (2009). Manajemen Kurikulum. Jakarta: Rajawali Pers

Prastowo, Andi. (2018). Sumber Belajar \& Pusat Sumber Belajar Teori dan Aplikasinya di Sekolah/Madrasah. Depok: Prenadamedia Group

Sugiyono. (2016). Metodologi Penelitian Kuantitatif, Kualitatif, dan R\&D. Bandung: CV Alfabeta

Sugiyono. (2017). Metodologi Penelitian Kuantitatif, Kualitatif, dan Kombinasi (Mixed Methods).Bandung: Alfabeta

Sugiyono. (2013). Metode Penelitian Kombinasi (Mixed Methods). Bandung: Alfabeta Arikunto, Suharsimi. (2010). Prosedur Penelitian Suatu Pendekatan Praktik. Jakarta: Rineka Cipta

Akbar, Sa'dun. (2013). Instrumen Perangkat Pembelajaran. Bandung: Remaja Rosdakarya. 